\title{
Da decodificação ao sentido: \\ a lei da imanência linguística e fatores discursivos na proficiência leitora
}

\author{
From decoding to meaning: \\ the law of linguistic immanence and discursive factors in reading proficiency
}

Patrícia Ribeiro de Andrade*

Universidade do Estado da Babia

Santo Antônio de Jesus, Bahia, Brasil

\begin{abstract}
Resumo: Neste texto, discutimos o problema da compreensão leitora, com o objetivo de auxiliar graduandos em Letras e professores pouco experientes, na difícil tarefa de promover o desenvolvimento da proficiência em leitura, por estudantes da Educação Básica. Realizamos, para tanto, um breve exercício de transposição didática, no qual se evidenciam dois níveis de construção do sentido, tomando como instrumento de estudo uma visão estruturalista da linguagem e a perspectiva discursiva bakhtiniana, para a prática de leitura, centrada no cotexto e no contexto discursivo, defendendo que, quanto mais conhecimento se busca, em torno da rede discursiva de um enunciado, maior e mais profunda é a compreensão deste discurso. Este material refere-se a uma comunicação que fizemos ao Congresso do Abralin em Cena, realizado em Feira de Santana, Bahia, no ano de 2018. Nesta oportunidade, ampliamos a discussão, com a finalidade de demonstrar dois aspectos importantes: em se tratando de prática pedagógica, as diferentes teorias podem se complementar para a construção de uma didática eficiente; ratificar a necessidade de que o componente de Língua Portuguesa tem como um dos principais atributos buscar formas de promover um constante e satisfatório exercício de compreensão discursivo-textual, atividade para qual a teoria dialógica bakhtiniana pode servir como um importante instrumento.
\end{abstract}

Palavras-chave: Leitura. Ensino. Aprendizagem. Dialógico. Texto.

Abstract: In this text, we discuss the problem of reading comprehension, with the objective of assisting undergraduate students of Letters and inexperienced teachers, in the difficult task of promoting the development of proficiency in reading by students of Basic Education. For this purpose, we carried out a brief didactic transposition exercise, in which two levels of meaning construction are evidenced, taking as a study tool a structuralist view of language and the Bakhtinian discursive perspective, for the practice of reading, centered on the text and the discursive context, arguing that the more knowledge is sought, around the discursive network of a statement, the greater and deeper the understanding of this discourse. This material referring to a communication we made to the Abralin em Cena Congress, held in Feira de Santana, Bahia, in the year 2018. In this opportunity, we expanded the discussion, in order to demonstrate two important aspects: when it comes to pedagogical practice, the different theories can complement each other for the construction of an efficient didactics; ratify the need for the Portuguese Language component as one of the main attributes to seek ways to promote a constant and satisfactory exercise of discursive-textual understanding, an activity for which the Bakhtinian dialogical theory can serve as an important instrument.

Keywords: Reading. Teaching. Learning. Dialogic. Text.

*Doutora em Linguística pela Pontifícia Universidade Católica do Rio Grande do Sul. Professora da Universidade do Estado da Bahia - Santo Antônio de Jesus, Bahia, Brasil. E-mail: patricia_campus5@yahoo.com.br. 


\section{TEORIA E PRÁTICA: UMA ARTICULAÇÃO POSSÍVEL E NECESSÁRIA}

Inquietações relacionadas à prática de leitura, com vistas ao desenvolvimento de uma proficiência satisfatória, são típicas de professores atuantes em todos os níveis de formação. Todavia, mais particularmente, entre os docentes da área de Letras essas inquietações se agudizam, uma vez que lidam, na graduação, com futuros professores de Língua Portuguesa e, na pós-graduação, com profissionais que, frequentemente, problematizam esse tema, tanto preocupados com a sua prática pedagógica vigente ou vindoura, quanto com a sua própria competência em ler, compreender e atribuir sentidos adequados aos textos e discursos com os quais lidam no dia a dia. Portanto, ainda que enxerguemos o campo da leitura como já bastante impregnado de discursos, o trabalho com o letramento parece não ser finito, posto que as diversas teorias e propostas pedagógicas criam-se e recriam-se em função das alteridades com quais nos deparamos no exercício da docência.

Neste artigo, propomos uma reflexão sobre a pertinência de teorias da linguagem para a prática de ensino da leitura. Para isso, apreciamos alguns aspectos da concepção formalista da linguagem e elementos da análise bakhtiniana do discurso, buscando demonstrar uma possiblidade de articulação entre essas vertentes, para auxílio didático do desenvolvimento da proficiência leitora por parte de discentes, em qualquer nível de formação.

As vertentes teóricas da Linguística não são facilmente conciliáveis, principalmente porque elas concebem a língua de diferentes formas e criam metodologias de análise muito específicas. Os acadêmicos dos cursos de Letras deparam-se, logo cedo, com essa diversidade e são frequentemente desafiados a criar instrumentos que lhes possibilitem transpor esse universo teórico para a abordagem prática. Atividade nada simples.

Atualmente, nos cursos de Letras, os discentes estudam, concomitantemente, em diferentes disciplinas, conteúdos da denominada linguística formalista e da linguística funcionalista, que trazem concepções de língua e linguagem bastante distintas entre si. E ainda, precisam estabelecer nexos entre todas essas diferenças e o ensino. Como nós, professores formados em linhas específicas, depois dos nossos cursos de strictu sensu, podemos ajudar nossos estudantes a elaborarem suas próprias tessituras, a partir desse emaranhado? Entendemos que o docente do curso de Letras não deve perder de vista esta problemática.

Pensamos que, aos recém-iniciados nos caminhos da Linguística, devemos oferecer um conhecimento o mais amplo possível, de questões filosóficas e históricas que estão no escopo de cada uma das vertentes linguísticas, tanto quanto ou até mais, do que se trabalha a metodologia de esquadrinhamento de usos da linguagem. Assim entendemos porque os fundamentos filosóficos e históricos suscitam responsividade, ou posicionamentos, de forma mais veemente que qualquer arcabouço metodológico, de modo a promover reflexões independentes.

Conforme Saussure, no que diz respeito à linguagem, é o olhar do analista que forja o objeto. Acreditamos que o conhecimento da arquitetônica filosófica das diversas perspectivas científicas que abordamos pode contribuir para que os discentes desenvolvam uma empatia em relação aos arcabouços teóricos e, talvez, seu próprio olhar, 
o que pode facilitar a sua tarefa de fazer as transposições didáticas que a atividade pedagógica exige.

É o que buscamos compartilhar a partir desta discussão.

\section{A COMPREENSÃO TEXTUAL: ABORDAGEM ESTRUTURALISTA E DISCURSIVA}

Independentemente da grande densidade inerente a todos os campos teóricos importantes, sabemos que na graduação, por promover formação latu senso, o docente precisa fazer recortes ao abordar perspectivas teóricas. Mas, certamente, tais recortes devem ser tão apreensíveis quanto possível, sem que se deixe de lado a essência de cada perspectiva e que suscite interesse, discordâncias, concordâncias e, no nosso caso em especial, que lidamos com formação de professores, que permita pensar em meios de transpor o conhecimento científico para os aprendizes da escola básica.

Para ilustrar, apresentamos um recorte de dois campos teóricos, aproveitando, panoramicamente, aqueles aspectos que servem à nossa intenção: articular o pensamento teórico ao ensino da leitura.

\subsection{PERSPECTIVA TEÓRICA ESTRUTURALISTA}

Em consonância com o que defendemos, iniciamos essa discussão teórica iluminando, de forma panorâmica, aspectos históricos e filosóficos que integram a base do chamado estruturalismo saussuriano e, posteriormente, da teoria dialógica bakhtiniana, as duas perspectivas que apoiam a análise que apresentamos mais adiante. Por uma opção didática, após cada abordagem teórica, desenvolvemos uma discussão de ordem prática.

Comecemos pela concepção de língua instaurada pela corrente formalista. Sabemos que, por exigências do momento histórico científico, Saussure fundou um arcabouço teórico e metodológico admirável, elevando a Linguística ao status de ciência, com a separação que fez entre a linguística interna, a qual permite a análise da língua fora do contexto sócio-histórico e a linguística externa, que leva em conta aspectos exteriores, como influenciadores do funcionamento do aparelho linguístico. São as conhecidas dicotomias entre língua e fala, sincronia e diacronia. As formulações feitas por Saussure são denominadas por seus críticos contemporâneos de objetivismo abstrato, possivelmente pela forma como o formalismo tornou palpável seu objeto de estudo, priorizando a explicitação das relações internas que os diversos níveis gramaticais mantêm entre si, não aleatoriamente, em perfeita harmonia sistêmica e livre de ocorrências situadas fora do organismo.

Bakhtin ([1929] 2006, p. 83), remete as origens do objetivismo abstrato ao racionalismo dos séculos XVII e XVIII, difundido pelo movimento neoclassicista que muito se inspirou na visão cartesiana, levando a filosofia da linguagem pelos caminhos do "culto da forma fixa, racional e imutável." Nas palavras do autor: 
Foi Leibniz quem exprimiu, pela primeira vez, estas idéias de forma clara, na sua teoria da gramática universal. A idéia de uma língua convencional, arbitrária é característica de toda corrente racionalista, bem como o paralelo estabelecido entre o código lingüístico e o código matemático. Ao espírito orientado para a matemática, dos racionalistas, o que interessa não é a relação do signo com a realidade por ele refletida ou com o indivíduo que o engendra, mas a relação de signo para signo no interior de um sistema fechado, e não obstante aceito e integrado. Em outras palavras, só lhes interessa a lógica interna do próprio sistema de signos [...]. (BAKHTIN, [1929] 2006, p. 85). [Grifos do autor].

O objetivismo abstrato imputa ao sistema linguístico a responsabilidade pela organização dos fatos da língua; ou seja, são os níveis fonético, gramatical e lexical que garantem o perfeito funcionamento da língua, enquanto organismo de uso coletivo, pois cada nível possui traços idênticos e comuns a todos, originários na própria norma linguística. Nessa perspectiva, o que diz respeito à variação é tido como desnecessário à ciência da linguagem, pois numa comunidade linguística, o que conta são os elementos linguísticos de referência, pela sua identidade normativa; os elementos variantes são "[...] processos individuais da fala, condicionados (do ponto de vista da língua como sistema) por fatores contingentes, fisiológicos e subjetivo-psicológicos, dos quais não podemos inteirar-nos com precisão." (BAKHTIN, [1929] 2006, p. 77-78).

Assim compreendido, o sistema linguístico é um objeto autônomo, sobre o qual o indivíduo não tem poder algum. As regras são categóricas e, qualquer uso individual da linguagem deve submeter-se a tais regras, do contrário tal uso não será encaixado no sistema, deixando de existir. Isto se dá porque a língua é governada por "[...] leis imanentes e especificas, irredutíveis a leis ideológicas, artísticas ou a quaisquer outras." (BAKHTIN, [1929] 2006, p. 79). [Grifos do autor].

$\mathrm{Na}$ linha saussuriana de compreensão do signo linguístico e das relações internas entre eles, Benveniste, desenvolve uma teorização sobre como o próprio sistema possibilita compreensão dos enunciados (novamente estamos diante das leis imanentes, às quais se refere Bakhtin). O que se dá, a princípio pela motivação semiótica da língua, através dos signos que a compõem. O signo é "[...] dotado de significação na comunidade daqueles que fazem uso de uma língua, e a totalidade destes signos forma a totalidade da língua.” (BENVENISTE, [1967] 1989, p. 227). Já o sentido daquilo que dizemos e ouvimos, na interação verbal, é função da unidade abstrata denominada frase que, segundo Benveniste, é a "expressão por excelência” do domínio semântico. "Não se trata mais, desta vez, do significado do signo, mas do que se pode chamar o intencionado. [...] A semiótica se caracteriza como uma propriedade da língua; a semântica resulta de uma atividade do locutor que coloca a língua em ação.” (BENVENISTE, [1967] 1989, p. 229).

Podemos compreender que, conforme Benveniste, a comunicação se faz pela confluência dos domínios semiótico e semântico: a) a propriedade que a língua tem de significar permite a seleção de signos, atividade do plano paradigmático de construção linguística; b) que, simultaneamente, à operação das relações associativas, entre os signos selecionados, ou seja, a relação que essas palavras mantêm entre si na cadeia sintagmática, de modo a remeter ao "aqui e agora", são criadas as condições fundamentais para a compreensão da mensagem. 
Observa-se que, ao contrário do que acontece no plano semiótico, em que um signo só precisa ser reconhecido como entidade de uma língua, no plano semântico, um simples reconhecimento não é o suficiente para compreensão do sentido de um enunciado. Segundo Benveniste, o "aqui e agora" são imprescindíveis, pois representam o "referente" que oferece ao interlocutor o suporte externo indispensável ao sucesso da comunicação, ou seja, a compreensão da mensagem.

[...] é necessário introduzir aqui um termo a que foi desnecessário apelar na análise semiótica: aquele do "referente", independente do sentido, e que é o objeto particular a que a palavra corresponde no caso concreto da circunstância ou do uso. Ainda que se compreenda o sentido individual das palavras, pode-se muito bem, fora da circunstância, não compreender o sentido que resulta da junção das palavras [...].

O sentido a transmitir, ou se se quiser, a mensagem é definida, delimitada, organizada por meio das palavras; e o sentido das palavras, por seu turno, se determina em relação ao contexto de situação. Ora, as palavras, instrumentos da expressão semântica, são materialmente os signos do repertório semiótico. Mas estes signos, em si mesmos conceptuais, genéricos, não circunstanciais, devem ser utilizados como "palavras" para noções sempre particulares, específicas, circunstanciais, nas acepções contingentes do discurso. (BENVENISTE, [1967] 1989, p. 231-233).

Aparentemente, a elaboração estruturalista de Benveniste permite um exercício adequado de compreensão da "mensagem" em si, por uma articulação entre fenômenos linguísticos internos e externos. As perspectivas teóricas que se sucederam à de Benveniste demonstram que o estruturalismo dá conta de uma relação restrita à referência exterior, mas é o sistema que conduz. (cf. OLIVEIRA, 2001; DUCROT, 1984, 1987, 1988). O significado, desse modo, não diz respeito a fatores relacionados ao falante, às suas intenções discursivas, ao universo ideológico que molda os discursos, ou à esfera dialógica a qual o discurso se vincula. Estes aspectos ultrapassam o domínio do sistema linguístico e, portanto, não desperta o interesse dos estudos tradicionalmente formais.

Obviamente, uma análise bibliográfica aprofundada em torno dos embasamentos oferecidos pelos autores mencionados, demandaria uma ampla discussão. Como nosso interesse é fazer um exercício de aplicabilidade, acreditamos que os pressupostos considerados nos bastam.

Analisemos, pois, um pequeno, mas denso poema, produzido no ano de 2018, no período em que o Brasil vivenciava as disputas eleitorais, aproveitando o suporte da concepção estruturalista de compreensão de mensagens. Adiante, depois da discussão de aspectos da teoria dialógica bakhtiniana, faremos outra leitura desse mesmo texto, orientando-nos pela perspectiva discursiva.

Façamos, então, a primeira leitura, embasada na concepção de língua, própria da linguística formalista.

\author{
(Re)volta \\ *Em memória do Mestre Moa do Katendê \\ Vamos voltar \\ Cinquenta anos atrás \\ Ou quem sabe mais...
}


Fazer emergir

Os navios negreiros

Erguer novos pelourinhos

Ou quem sabe mais...

Acender as fogueiras

De novas inquisições

Marcar os corpos

Com esdrúxulas inscrições

Ou quem sabe mais...

E, enfim,

(que pena...)

Voltaremos ao tempo

Em que será pecado

Escrever um poema. (J. C. Vaz) ${ }^{1}$

Numa primeira leitura, tendo por base a língua como estrutura, conforme promulga Benveniste, podemos ter uma compreensão do referente, que entendemos ser a liberdade ou a perda dela.

O segundo aspecto a observar é que todas as palavras integrantes do texto fazem parte do léxico da língua portuguesa. $\mathrm{E}$, ainda que, de algumas palavras se desconheça o significado, é improvável que o leitor não as considere como não pertencentes ao léxico português. Além do mais, isso não representa um problema, uma vez que os dicionários podem auxiliar na compreensão de verbetes desconhecidos.

Ao contemplarmos o título, "(Re)volta", temos o uso de um recurso gráfico que remete ao processo de formação de palavras através da derivação. Sem nenhuma necessidade de extrapolação dos limites do código linguístico, temos um significado possível de ser construído: o título cria um jogo de palavras, em que o leitor é remetido tanto ao retorno a algo ou algum tempo, quanto à ideia de insurgência.

Em seguida, nos deparamos com uma menção exterior ao texto, que é a dedicatória do poema ao "Mestre Moa do Katendê", momento em que o co-texto sozinho não dá conta da compreensão. Necessitamos de informações fora dos limites do texto, se desejamos fazer uma leitura mais eficaz. Cabe, portanto, acessar conhecimentos do contexto extra-verbal, situado no "aqui e agora" para que a enunciação advinda do poema se torne explícita.

Quem é o Mestre Moa do Katendê? Foi compositor, dançarino, capoeirista, artesão e propagador da cultura afro-brasileira. Completaria 64 anos de vida no dia 29 do mês de outubro de 2018, entretanto, foi assassinado com doze facadas pelas costas, depois de uma discussão sobre política.

\footnotetext{
${ }^{1}$ José Vaz Souza Miranda é bacharel em Segurança Pública, Especialista em Polícia Comunitária com ênfase em Ouvidoria. Atualmente, é acadêmico do Curso de Letras - Português - UNEB - Campus V. Poeta, membro da Academia de Letras do Recôncavo. Autor, entre outros, de "Nas teclas do coração" e de "Catarse".
} 
Isso dito, tomemos a primeira estrofe do poema, na qual lemos: Vamos voltar/Cinquenta anos atrás/Ou quem sabe mais...

Verificamos que os dois primeiros versos trazem uma afirmação, uma declaração, uma assertiva, uma constatação ou mesmo um convite (ainda que a construção verbal esteja no modo indicativo) de retorno a um tempo pretérito específico - cinquenta anos atrás. Retomando o título, a partir da palavra primitiva dele participante, "volta", podemos observar que a proposta do texto é, de fato, uma volta, a um determinado momento que, provavelmente, é presumido como sendo conhecido pelo leitor. Todavia, o terceiro verso indica que esse retorno pode ser para além dos já longínquos cinquenta anos mencionados.

Os versos seguintes nos trazem maiores informações sobre o significado linguístico da "volta", evidenciando qual das possibilidades de significado, dentre as anteriormente elencadas, melhor se encaixa, para a compreensão do texto: Faz̧er emergir/Os navios negreiros/Erguer novos pelourinhos/Ou quem sabe mais...

O verso "Ou que sabe mais" lança o leitor para outro período específico, o da escravização de povos africanos. Período que estava submerso, conforme sugerem os versos Fazer emergir/ Os navios negreiros. Os navios negreiros são um dos mais emblemáticos símbolos da escravização, que ressurgem, no poema, através de uma fortíssima imagem. E com a volta dos navios negreiros, outro símbolo notório vem à tona: os pelourinhos, ou o tronco, o instrumento de tortura e violência física imposta ao escravizado insurgente ou fugitivo.

O texto do poema propõe, mais uma vez, a volta a um passado ainda mais distante, conforme os versos Acender as fogueiras/De novas inquisiçöes.

Observemos que o verbo "vamos" é o organizador textual, de modo a demonstrar que todas as sequências de eventos relatados representam atos coletivos, sejam na forma de constatação ou na condição de um convite. É pela mão de uma coletividade que a "volta" será possível.

Essa volta a um passado longínquo, mas determinado, está registrado no emprego de "fogueiras da inquisição". Contudo, não as fogueiras da Santa Inquisição, mas outras, "novas" fogueiras, indicando que o ato de outrora se repetirá de forma diversa. Nesses trechos, o poema deixa revelar o significado da palavra derivada "(Re)volta" que consta do título. Há algo gerando descontentamento e isso se anuncia mediante imagens conhecidas pela história que, ao que o texto indica, voltarão a ser vivenciadas, pelo ressurgimento de navios negreiros, reestabelecimento dos pelourinhos, com o atear fogo a pessoas através de "novas fogueiras da inquisição".

O sentimento de revolta fica mais evidente nos versos seguintes, com mais um prenúncio sombrio: o cravar a corpos sinais estranhos devido a uma atitude talvez de insubmissão; é um castigo. E, por se tratar de uma volta, sempre é possível vivenciar-se algo cada vez pior, conforme lemos no recorrente verso "Ou quem sabe mais..."

$\mathrm{Na}$ última estrofe, o futuro verbal serve para arrematar o retrocesso vindouro: Voltaremos ao tempo/Em que será... No presente não se vivencia a escravização histórica, nem o flagelo da Inquisição, nem a proibição da expressão pela palavra (Em que será pecado/Escrever um poema). O destaque "que pena..." explicita uma profunda lamentação pela volta a um estado de proibição, seja pelas mãos da "igreja” (...será pecado), seja pelas 
mãos de um estado repressor, conforme podemos apreender, agora, a partir da primeira estrofe. "Cinquenta anos atrás" remonta a um período histórico que, no caso do Brasil, foi a época da ditadura militar, em que a liberdade de expressão foi intensamente tolhida.

Reconstruindo o texto, considerando apenas o sistema em si, podemos afirmar: a volta causa revolta, pelo retorno a tempos reconhecidamente criminosos, que se associam à ditadura, escravidão, tortura e, o pior, ao silenciamento forçado, ante as atrocidades que esses tempos representaram.

Devemos enfatizar, ainda, que a imersão da coletividade em tempos cada vez mais remotos e sombrios, se dá pelo recurso poético recorrente do verso "Ou quem sabe mais...”. De fato, a cada vez que, no poema, tal repetição se faz, as imagens criadas são de um aprofundamento num estado de coisas cada vez mais tenebroso.

Associemos, também, a dedicatória do poema ao seu título: “(Re)volta”. Todos os aspectos apresentados no texto podem se vincular a um espírito de revolta, pelo retorno da sociedade a tempos horripilantes, de intolerância que, conforme entendemos, deram origem ao assassinato de um homem negro, ativista, engajado na luta pela defesa de pessoas marginalizadas e também pela proteção à cultura afro-brasileira.

\subsection{TEORIA DIALÓGICA DO DISCURSO}

Se na perspectiva anteriormente abordada, a primazia do estudo da compreensão está no sistema linguístico, a teoria que ora passamos a observar focaliza a "mensagem" como discurso, objeto construído e compreendido no bojo da interação verbal. A teorização da linguagem elaborada pelo Círculo de Bakhtin ${ }^{2}$ diferencia-se imensamente da linguística saussuriana, em diversos aspectos, desde a concepção do objeto, sua relação com os falantes e com a vida, a organização interna e externa da linguagem em ação, entre outros.

Saussure e seus seguidores abstraíram da abordagem linguística a enunciação, que é a face inerente aos interlocutores. O seu sucessor, Benveniste, buscou dar vez ao significado, propondo a transmutação do signo em palavra, quando da língua em funcionamento. Desse modo, forma-se o "referente" a ser identificado, para que a "mensagem" seja compreendida. Já Bakhtin e o seu Círculo fundaram uma filosofia da linguagem, na qual se toma o discurso como objeto de estudo. Por se tratar de uma filosofia, a perspectiva bakhtiniana é não excludente. Podemos afirmar que a concepção de língua inaugurada por esses estudiosos a estabeleceu como um macro-objeto, uma vez que pode conter em si outros níveis de análise, a propósito da que se realiza na abordagem formalista.

Nesse caso, o que diferencia o objeto de análise do estruturalismo do objeto bakhtiniano é que o discurso é, efetivamente, tomado como uma atividade humana, logo, não se desvencilha da história, das esferas comunicativas, dos interlocutores, nem do

\footnotetext{
2 O Círculo de Bakhtin constituiu-se por intelectuais, cientistas com formação diversa e artistas de vários lugares da Rússia, entre os anos de 1918 e 1929. Bakhtin é considerado o principal represente desse grupo, razão por que, frequente faz-se referência ao grupo como "Bakhtin e o seu Círculo".
} 
objeto sobre o qual versa a interação. O trecho a seguir explica porque consideramos o discurso um macro-objeto.

\begin{abstract}
A língua vive e evolui historicamente na comunicação verbal concreta, não no sistema lingüístico abstrato das formas da língua nem no psiquismo individual dos falantes. Disso decorre que a ordem metodológica para o estudo da língua deve ser o seguinte: 1 . As formas e os tipos de interação verbal em ligação com as condições concretas em que se realiza. 2 . As formas das distintas enunciações, dos atos de fala isolados em ligação estreita com a interação de que constituem os elementos, isto é, as categorias de atos de fala na vida e na criação ideológica que se prestam a uma determinação pela interação verbal. 3. A partir daí, exame das formas da língua na sua interpretação lingüística habitual. (BAKHTIN, [1929], 2006, p. 127).
\end{abstract}

De forma objetiva, para fins de análise, consideremos algumas propriedades do discurso, postuladas pelo Círculo.

O discurso é social e se constitui de outros discursos, ou de vozes sociais, denominação que compreende a interação entre indivíduos concretizada na vida. As vozes sociais integram o discurso, imprimindo marcas do plurilinguismo, de visões divergentes e convergentes sobre o objeto, de novas formas de conceber esse objeto, de posicionamentos responsivos (DI FANTI, 2003). Não construímos mensagens em torno de um vácuo. A enunciação sempre está a serviço de uma resposta a algum evento verbal ou não verbal que suscita um posicionamento.

$\mathrm{Na}$ obra de Bakhtin, é recorrente a imagem virtual da rede discursiva da qual um discurso faz parte, de forma a iluminar ou obscurecer o discurso de outrem, a "palavra alheia" com a finalidade de, em resposta a tais enunciações, expor uma posição, seja de discordância, concordância, ampliação, etc.. Por essa função, a de dar respostas ou antecipá-las, já que todo discurso pressupõe o que a teoria denomina de atitude responsiva, até mesmo gestos e silêncios são elementos da construção discursiva. Essa relação que os discursos mantêm entre si é uma propriedade da linguagem, o dialogismo, que possibilita a compreensão da enunciação e da qual não devemos abrir mão se quisermos construir sentidos. Essa função é a face externa do discurso.

Internamente, o discurso tem como unidade o enunciado. E o enunciado pode se constituir como o próprio discurso, numa dada situação interativa. Embora em alguns casos haja coincidência entre enunciado e frase, não devemos confundir as duas coisas. A frase é uma unidade da linguística estrutural e é uma convenção para fins de análise, tanto que os seus limites e sua definição podem ser facilmente estabelecidos e observados, pois ela compõe a estrutura textual e está em estreita relação com outras frases do mesmo texto. Noutras palavras, a frase é um elemento do co-texto, ou podemos dizer também do contexto interno e serve para dar sequência aos argumentos do texto.

O enunciado, por sua vez, contém a frase, pois esta unidade estrutura os textos e os discursos. Por outro lado, o enunciado se relaciona com o contexto discursivo, não tem limites objetivamente demarcados, posto que responde a uma situação supra textual. Em qualquer situação dialogal encontramos essa unidade discursiva, projetada na 
alternância entre os interlocutores de uma conversa. O professor, por exemplo, constrói seu discurso, retomando outros discursos e posicionando-se sobre eles, numa atitude responsiva. Seus alunos podem "tomar de assalto" sua palavra, também numa atitude responsiva, apresentando considerações sobre o tema em voga. Cada uma das enunciações que são acionadas pelas partes, durante a aula, compõe o discurso dessa interação e esse discurso vai, possivelmente, dar vida a textos, que são discursos específicos, de cada um dos participantes.

Os enunciados são organizados por gêneros discursivos, outro aspecto pertinente no estudo do discurso. A enunciação se dá em função da situação interativa (esferas), concretizada em gêneros do discurso. E, a todos os campos da atividade humana vinculam-se gêneros discursivos com tons que lhes são próprios, devido ao seu "conteúdo temático, estilo e construção composicional”, conforme salienta Bakhtin (2010, p. 262).

Uma análise baseada na teoria dialógica discursiva da linguagem deve considerar que o signo é ideológico. Por ser a palavra o lugar da ideologia por excelência, sempre que a língua está em ação, há que se buscar explicitar essa ideologia, pois se trata de um forte componente interpretativo. Não se trata apenas de ideologias político-partidárias, mas também do discurso mais rotineiro e trivial do nosso entorno. Estamos sempre escolhendo as palavras "certas", monitorando a nossa entoação ao proferir alguma coisa, levando em conta a situação, os nossos interlocutores, organizando mentalmente o conteúdo, para que seja "bem" compreendido. De outra forma, preocupamo-nos quase o tempo inteiro com os constituintes do gênero (estilo, construção composicional e conteúdo) que estamos acionando, porque eles depõem sobre nós, daí o caráter ideológico das formas de comunicar, mesmo aquelas consideradas "neutras".

Consideremos esses aspectos, na perspectiva do poema "(Re)volta”. Ao tomá-lo como um texto que dialoga com outros discursos, vem à baila uma quantidade relevante de informações que circularam no entorno social, sobretudo, através das mídias não convencionais, as quais contribuíram enormemente para uma animosidade entre os brasileiros, no período eleitoral. Com base nisso, verificamos que o discurso prevalente no texto é político, da primeira à última linha.

Primeiro, a dedicatória do poema ao Mestre Moa do Katendê já demonstra, juntamente com o título, um explícito descontentamento com um então provável governo de extrema direita, fato que acabou se confirmando, com a eleição do candidato Bolsonaro. Notamos essa resistência, logo de início, porque temos ciência de que o assassinato do capoeirista se deu em função de ele declarar seu voto ao candidato rival de Bolsonaro, Fernando Haddad. Portanto, tão logo colocamos os olhos no texto, já podemos entrever um conteúdo que expressa certo posicionamento político antagônico ao bolsonarismo. Além desses elementos pré-textuais, a primeira estrofe dialoga explicitamente com o discurso do candidato, que proferiu, em várias oportunidades, seu desejo de ter uma sociedade sob o domínio da ditadura militar. Ou seja, voltar cinquenta anos é voltar a um período em que o país esteve sob o domínio do poder militar, cujas consequências são notórias.

Quanto ao gênero, o discurso contido em "(Re)volta" é uma expressão de ordem estética poética, identificada, a princípio pela forma como está disposto graficamente, depois pela entoação, ao gosto artístico, promovendo uma fruição de construção 
imagética. Como qualquer outro discurso, a obra poética está intimamente vinculada ao contexto social, razão pela qual o locutor não deve presumir que seus interlocutores interajam com o seu discurso "esvaziados de qualquer horizonte unificante". (VOLOSHINOV; BAKHTIN, 1926, p. 10). Assim, o locutor dá forma ao seu discurso, verbalizando ou gesticulando, escolhendo um "tom" alicerçado na crença de que o enunciado se repercutirá consoante seu objetivo, por supor que sua visão de mundo é compartilhada e por ter ciência de que seu discurso se forja numa determinada esfera. A esfera discursiva apoia-se no presumido, correspondente ao "aqui e agora", acrescido de interlocutores, que certamente promove a "economia" linguística e torna, por vezes, a ideologia pouco saliente nas interações verbais, sobretudo, em situações comuns das relações humanas.

Os sentidos que damos aos enunciados pautam-se em julgamentos e avaliações que advêm tanto da individualidade e subjetividade de seus produtores e interlocutores, quanto de aspectos sociais e objetivos que envolvem os discursos: "Esses julgamentos e avaliações referem-se a um certo todo dentro do qual o discurso verbal envolve diretamente um evento na vida, e funde-se com este evento, formando uma unidade indissolúvel." (VOLOSHINOV; BAKHTIN, 1926, p. 5).

Compreendemos um discurso a partir do conhecimento que temos de mundo, construindo sentidos que pensamos ser inequívocos, sem que para isso o locutor precise explicitar todas as informações, em função do presumido. Não é, portanto, sem motivo que cada interlocutor constrói sentidos diferentes, dependendo das vias pelas quais participa do debate sobre o objeto, ou ainda se ignora esse objeto. Mas, o "horizonte unificante", primeiro garantido pelas propriedades semiótica, semântica e estruturante da língua, depois, em função da "força gravitacional" da esfera discursiva, sempre garantirá algum entendimento entre os interlocutores, por mais diversas que sejam suas interpretações.

Desse modo, esperamos que o leitor compartilhe conosco o entendimento de que o texto "(Re)volta" é um manifesto em favor da democracia. E por que a democracia estaria em risco, suscitando uma defesa? Vejamos.

A volta à época da escravidão é uma alusão ao discurso do presidente eleito em 2018, sobre a revogação das leis trabalhistas em vigor no Brasil. Bolsonaro afirma, veementemente, que o desemprego no país tem a ver com o excesso de direitos do trabalhador garantidos por lei. Então, a proposta dele é que se abra mão dos direitos, para se recuperar o emprego. Entendemos que retorno à escravidão provavelmente está associada a essa proposta de retirada de direitos.

As "marcas esdrúxulas" podem ser compreendidas a partir de outro acontecimento contemporâneo, que ocupou os noticiários. Uma garota identificada com a causa LGBT, que está em foco no país, teve seu pescoço (ou sua barriga - há desencontro de informações sobre o fato) tatuado com a suástica, símbolo nazista. Mais uma vez é de se observar a discordância do discurso contido em "(Re)volta", em relação ao que prega os apoiadores de extrema direita, que se sentem contemplados pela proposta bolsonarista de governança, os quais desejam um país que negue a sua diversidade. Bolsonaro, em campanha, garantiu ao seu séquito que os valores tradicionais das maiorias politicamente representativas (família convencional, homens, heterossexuais, brancos, ricos, cristãos) se 
sobreporiam aos das minorias politicamente sub-representadas (pobres, negros, índios, mulheres, segmento LGBT, de religiões não cristãs).

A última estrofe, E, enfim,/ (que pena...)/Voltaremos ao tempo/Em que será pecado/Escrever um poema, é o desfecho do povir, que podemos compreender como um desalentador alerta: apesar de todo o infortúnio que se prenuncia, ao ignorarmos os sinais, no futuro nada poderá ser dito.

Para complementar, apresentamos na próxima seção uma sugestão de atividades de compreensão leitora, tomando como parâmetro requisitos estabelecidos pelo Programa Nacional do Livro Didático (PNLD).

\subsection{PROPOSTA DE ATIVIDADES DE COMPREENSÃO DO TEXTO}

Desde os anos de 1970, as ciências da linguagem discutem problemas relacionados à compreensão de enunciados, aos mecanismos de funcionamento do texto, à tipologia textual, à textualidade, enquanto as ciências do aprendizado da leitura já ofereciam também conhecimento sobre compreensão, sujeito cognitivo e sua capacidade de fazer inferências e usar a linguagem de forma produtiva e criativa. Em contrapartida, o estado brasileiro incrementou as ações do Programa Nacional do Livro Didático (PNLD), entre elas a avaliação de livros didáticos, no sentido de estabelecer critérios que seguiriam esses avanços, visando à promoção de um ensino e aprendizado de qualidade.

Em relação à área de linguagem, estabeleceu-se que a prática de leitura passaria a ser ela mesma um objeto de ensino e aprendizado. O estudo do texto deveria partir da concepção de que esse objeto é uma realização discursiva, demandando um trabalho notadamente mais complexo, voltado para a própria produção do texto, a sua constituição enquanto unidade de sentido, cabendo explicitar os meios que o produtor utiliza para essa construção, as condições sociais e históricas que envolvem essa produção, a fim de se (re)construir, efetivamente, o sentido do discurso.

Nessa perspectiva, a prática de leitura deve ser feita mediante o trabalho com aspectos, como: o favorecimento de experiências significativas de leitura; abordagem da diversidade de esferas e gêneros discursivos; inclusão de textos multimodais; discussão de temas que contemplem a heterogeneidade sociocultural brasileira, quanto à faixa etária, etnia, gênero, classe social, região, etc.

Para ilustrar, propomos, a seguir, questões que podem guiar a abordagem interpretativa, aproveitando o texto "(Re)volta", observando as sugestões que se estabelecem para avaliação do eixo da leitura, conforme "Ficha Consolidada da Coleção" (PNLD 2015).

i) Finalidade: resgate do contexto de produção (contexto histórico, função social, esfera discursiva, suporte, autor e obra)

a) Vamos falar um pouco do autor do texto. Qual a sua formação? Ele possui outras obras? O seu trabalho tem um reconhecimento formal? 
b) Em que ano o poema foi produzido? Como podemos saber disso?

c) A quem o poema pode interessar?

d) Quais acontecimentos sociais se relacionam com o texto?

ii) Finalidade: observação da materialidade do texto:

a) É interessante a forma como o texto é trabalhado, do ponto de vista composicional?

b) Quais recursos gráficos observamos na construção textual?

c) Por que será que esses recursos foram utilizados? Para que servem?

d) Por que o título está construído com parênteses? Qual o significado do "(Re)"?

d) Qual o tema abordado? Podemos abstrair um objeto do discurso poético?

e) Verificamos a presença de aspectos éticos, políticos, ideológicos?

f) O conteúdo do texto faz referência à forma como o brasileiro lida com a diversidade de pensamentos?

g) Que elementos fazem desse texto um poema?

h) Quais traços marcam o estilo no texto?

i) Existem temas mais poéticos e menos poéticos?

iii) Finalidade: trabalho para o desenvolvimento da proficiência leitora:

a) O que sabemos do Mestre Moa do Katendê?

b) Será que o texto vai falar do Mestre Moa?

c) Após a leitura, que relações podemos estabelecer entre a dedicatória do poema e o conteúdo?

d) O conteúdo diz respeito especificamente ao homenageado?

e) Que assuntos o discurso de "(Re)volta" nos permite discutir?

f) É possível estabelecermos uma sequência de eventos?

g) As estrofes mantêm uma progressividade entre sì?

h) As estrofes são enunciados independentes?

i) Podemos relacionar os eventos do texto a outros eventos que conhecemos?

j) Há outros textos que tratam do mesmo conteúdo? Vamos pesquisar?

Além das atividades destinadas à compreensão leitora, sabemos que o ensino de língua, na atualidade, demanda a articulação entre o ensino de produção oral e escrita e de conhecimentos linguísticos de forma articulada. Acreditamos que um estudo amplo do texto, por si só, pode favorecer os demais eixos de ensino e aprendizado, tornando o aprendizado um bem inestimável para os nossos estudantes.

\section{UM PONTO FINAL DIDÁTICO}

Há tanto a ser feito, desfeito e refeito no nosso campo de atuação que consideramos pertinente apropriar-nos da expressão "ponto final didático", cunhado pela professora Profa. Dra. Maria Inês Corte Vitória (PUCRS - FACED), durante nossa defesa de tese. De fato, ao finalizarmos um trabalho, a certeza que temos é a de sua incompletude. Mas, quem nesta vida pode dar por finalizada a sua trajetória, se a nossa missão é a ininterrupta 
“atividade humana”? Devemos, pois, saturá-la de pontos finais didáticos, para quê nunca paremos, enquanto respirarmos.

E como parar, se o ato de educar ganha novas facetas a todo instante? Atualmente, por exemplo, deveríamos estar consolidando a trajetória que se iniciou com a Constituição Cidadã de 1988, na qual lemos no artigo 205: "A educação, direito de todos e dever do Estado e da família, será promovida e incentivada com a colaboração da sociedade, visando ao pleno desenvolvimento da pessoa, seu preparo para o exercício da cidadania e sua qualificação para o trabalho". E merecíamos, também, estar colhendo os frutos de um intenso trabalho acadêmico que se iniciou nos anos finais do século XX, na luta por uma educação de qualidade.

Ao invés disso, nosso trabalho se agigantou, porque estamos vivenciando uma apologia à ignorância, que vai desde o questionamento do formato da Terra (há quem esteja acreditando que ela é plana!), até a negação da deterioração do clima e esgotamento dos recursos naturais. E o que dizer da proposta de o Brasil ir na contramão de quase todo o planeta, no que se refere à contenção da pandemia causada pelo coronavírus? Não devemos nos esquecer que tais absurdos, totalmente anti-científicos, são apregoados paralelamente à desvalorização do trabalho do professor, sobretudo o do ensino superior.

Então, a nossa responsabilidade não deve mais ficar restrita aos específicos afazeres escolares. A investida contra o mundo que ajudamos a construir convoca-nos à participação do grande debate social, a defesa da democracia, que abriga a defesa da ciência, da cidadania, dos direitos humanos... E a principal bandeira dessa luta é a educação.

Dentro dos muros da escola, devemos criar obstáculos a esse projeto de desmanche e, como Jó Joaquim, personagem do "Desenredo" de Guimarães Rosa, ir desconstruindo, pacientemente, os aforismos da sanha extremista que vem para nos esmorecer, deprimir e nos vencer.

Nessa luta de resistência, um importante aliado é o trabalho por um aprendizado qualificado e isso passa, forçosamente, pela prática de leitura. Cabe-nos munir de conhecimento, o máximo que pudermos o nosso estudante, através da leitura de textos prazerosos, ricos em informação, em estética, ética e criticidade.

Acreditamos, com este trabalho, estarmos sendo coerentes com nossa posição política, visto que discutimos o problema da compreensão leitora, de modo a atender a uma demanda dos estudantes de graduação e pós-graduação em Letras, que sentem dificuldades em realizar a transposição didática, entre o conhecimento teórico adquirido nos cursos e a sua realidade objetiva, como também estudantes que precisam apreender os conteúdos das disciplinas e desenvolver uma prática pedagógica que favoreça o aprendizado e contemple as necessidades da atualidade.

Visando a contribuir para a construção em torno da prática leitora, propusemos uma reflexão sobre duas correntes teóricas diversas entre si, mas que podem manter uma relação de complementaridade, de forma a auxiliar no exercício do estabelecimento do sentido de textos e discursos. Apresentamos, então, uma visão panorâmica da teoria estruturalista e da perspectiva teórica discursiva de Bakhtin e o seu Círculo, no que tange ao problema da compreensão de textos e discursos. 
Com base em tais perspectivas, realizamos a análise de um poema, buscando demonstrar que, para o trabalho com a leitura, tanto uma visão do sistema, como uma reflexão social podem ser igualmente importantes para o desenvolvimento da proficiência leitora. Além disso, apresentamos sugestão de atividades que recobrem várias facetas do desenvolvimento cognitivo, linguístico e social do aprendizado da leitura.

\section{REFERÊNCIAS BIBLIOGRÁFICAS}

BAKHTIN, M. Estética da criação verbal. 5. ed. São Paulo: Martins Fontes, 2010.

BAKHTIN, M. Marxismo e filosofia da linguagem (1929). 12. ed. Hucitec, 2006. http//:www.fecra.edu.br/admin/arquivos/MARXISMO_E_FILOSOFIA_DA_LING UAGEM.pdf . Acesso em: 10 out. 2018.

BENVENISTE, É. (1967). Forma e sentido na linguagem. Problemas de lingüistica geral II. Campinas, Pontes. 1989. p. 220-242.

DI FANTI, M. da G. C.. A linguagem em Bakhtin: pontos e pespontos. Revista de Estudos Linguisticos Veredas, Juiz de Fora, v.7, n.1 e n.2, p.95-111, jan./dez. 2003.

DUCROT, O. Polifonía y argumentación. Cali: Universidad del Valle, 1988.

DUCROT, O. O dizer e o dito. Revisão técnica da tradução: Eduardo Guimarães. Campinas, SP: Pontes, 1987.

DUCROT, O. Enunciação. Enciclopédia Einaudi, v. 2. Lisboa: Imprensa Nacional, Casa da Moeda, 1984.

OLIVEIRA, R. P. de. Semântica. MUSSALIN, Fernanada; BENTES, Anna Christina (orgs.). Introdução à linguística: domínios e fronteiras. 2. ed. São Paulo: Cortez, 2001.

PNLD 2015. Língua portuguesa (Ensino Médio). Ficha consolidada da coleção. Universidade Federal de Minas Gerais - Faculdade de Letras, Belo Horizonte: 2015 (mimeo).

VOLOSHINOV, V. N.; BAKHTIN, M. (1926). Discurso na vida e discurso na arte. Trad. para fins didáticos de Carlos Alberto Faraco e Cristóvão Tezza. s.d. 